DOI 10.37882/2500-3682.2021.07.13

\title{
АТРИБУТИВНАЯ МОДЕЛЬ СТРАДАНИЯ В ВОСТОЧНОЙ ФИЛОСОФИИ И В ИРРАЦИОНАЛИЗМЕ А. ШОПЕНГАУЭРА
}

\section{ATTRIBUTIVE MODEL OF SUFFERING IN EASTERN PHILOSOPHY AND IN A. SCHOPENHAUER'S IRRATIONALISM \\ D. Tokarev}

Summary: The article describes the attributive model of suffering, which includes, in accordance with General principles and ideas, approaches and manifestations, various directions of ancient Eastern philosophy and religion, in particular, «Bhagavad Gita», Jainism, Buddhism, Taoism, for which this is most characteristic, and also considers the irrationalist teaching of Arthur Schopenhauer, regarding the relationship to suffering as an attribute of human life and having some similarities with Eastern religious and philosophical concepts. Within the framework of the ancient Eastern philosophical tradition, the causes of suffering, its manifestations, and possible options for liberation from suffering are analyzed. The article presents the philosophical view of Arthur Schopenhauer on the causality of suffering and its relationship with hedonistic manifestations in human life. The research focuses on suffering as an attribute of human life, as well as the characteristics of human behavior inherent in this state. Emphasis is placed on finding a way out of the state of suffering through religious meditation or awareness of the finiteness of suffering with the onset of death. Specific aspects of the consideration of suffering in the context of this model are revealed, including the belief in the possibility of another life, the understanding of suffering as a necessary condition that contributes to the life wisdom of a person, the attribution inherent in suffering in a person's life, which allows one to come to terms with its presence and positive, purifying meaning. In this paper, we identify significant shortcomings characteristic of the presented attributive view, in particular, passive doom, which, with certain psychological and other problems, can lead to the desire to leave life. The attribution of suffering reduces the value of social interaction, the suffering person remains alone with himself, which is all the more dangerous in modern conditions of social disunity and virtual space.

Keywords: suffering, attribution, vitality, sources of suffering, possibilities of liberation from suffering.
Токарев Дмитрий Анатольевич

К.ф.н., доцент, Омский институт водного транспорта (филиал) ФГБОУ ВО «Сибирский государственный университет водного транспорта», г. Омск mityatokarev@mail.ru

Аннотация: B статье дана характеристика атрибутивной модели страдания, к которой отнесены, в соответствии с общими принципами и идеями, подходами и проявлениями, различные направления древней восточной философии и религии, в частности, «Бхагавадгита», джайнизм, буддизм, даосизм, для которых это наиболее характерно, а также рассмотрено иррационалистическое учение Артура Шопенгауэра, касаемо отношения к страданию как атрибуту жизни человека и имеющее некоторое сходство с восточными религиозно-философскими концепциями. Проанализированы в рамках древней восточной философской традиции причины возникновения страдания, его проявления и возможные варианты освобождения от страданий. Представлен философский взгляд Артура Шопенгауэра на причинность страдания и его взаимосвязь с гедонистическими проявлениями в жизни человека. В центре исследования страдание как атрибут жизни человека, а также, присущие этому состоянию характеристики человеческого поведения. Сделан акцент на поиске выхода из состояния страдания через религиозную медитацию или осознание конечности страданий с наступлением смерти. Выявлены специфические стороны рассмотрения страдания в контексте данной модели, среди которых, вера в возможность другой жизни, понимание страдания как необходимого условия, способствующего жизненной мудрости человека, присущее страданию атрибутивность в жизни человека, позволяющая смириться с его присутствием и позитивным, очищающим смыслом. В данной работе обозначены существенные недостатки характерные для представленного атрибутивного взгляда, в частности, страдательная обреченность, которая, при определенных психологических и других проблемах, может привести и к стремлению ухода из жизни. Атрибутивность страдания уменьшает ценность социального взаимодействия, страдающий человек остается с самим собой наедине, что тем более опасно в современных условиях социальной разобщенности и виртуального пространства.

Ключевые слова: страдание, атрибутивность, витальность, источники страдания, возможности освобождения от страдания. традание и его проявления в человеческой жизни - важная часть глубокого философского осмысливания действительности, переживаний человека, во многом определяющая составляющая самых разнообразных философских и религиозных направлений. Предполагается несколько различных моделей трактовки причин страдания и путей освобождения от него. Особо необходимо выделить атрибутивную модель страдания, которая имеет серьезные отличия в рассмотрении причин страдания, его проявлений и в особенности возможностей преодоления страдания от, например, модусной модели, включающей христианскую сотериологическую теорию спасения человека и экзистенциальный вариант подлинного существования [1, с. 4; 110; 111]. Наиболее ранней по появлению и формированию, чем в частности и вызвано данное исследование, а также и яркой по содержанию, является атрибутивная модель страдания, для которой характерно представление страдания как обязательного атрибута земной жизни человека и преодоление этого атрибута 
возможно только при переходе в другие состояния, выходящие за обыденные рамки земной жизни. Без страдания нет человека и нет его просветления, ухода от всех земных проблем и переживаний. Проанализируем атрибутивную модель страдания, на примере наиболее ярко выраженных в данном контексте, религиозно-философских концепций Древнего Востока и иррационального учения Артура Шопенгауэра. Цель представленного исследования - определить позитивные стороны атрибутивности страдания и выявить особенности негативного влияния атрибутивности проявлений и преодоления страдания для современного человека.

К атрибутивной модели страдания, прежде всего, можно отнести различные направления древнеиндийской религиозно-философской мысли, среди которых можно особо выделить «Бхагавадгиту» - одно из самых важных литературно-философских произведений древности. Фактически этот текст олицетворение идеального союза религиозных представлений того времени с философским анализом, которым уже обладали люди той эпохи.

Понятие страдания представлено в «Бхагавадгите» словами Кришны в ответ на вопросы своих собеседников. Во многом это этическое обращение к людям, желающим преодолеть свои сомнения. В данном произведении философской и религиозной мысли подчеркивается, что страдания и радости не вечны, к ним надо относиться безучастно, ибо бессмертья способно достичь лишь в ровном восприятии каких-либо ярких эмоций и переживаний [2, с.102]. Отношение к миру в философии Древней Индии было как данности, как к непреходящему, а значит, уничтожить это никто не может, так зачем излишне выбрасывать из себя эмоции страдания и радости. Если тело бренно в этом мире, то оно все равно переходит в другое состояние, продолжает жизнь, но в другом качестве. Человеческая душа вечна лишь потому, что она готова ко всем переходам, она не требует невероятных усилий, просто надо воспринять спокойно, возможно есть что-то другое.

Во многом трактовка понятия страдания в «Бхагавадгите» схожа с трактовкой в упанишадах и в этом проявляется монолитность всей индийской религиозно-философской мысли. Страдание, безусловно, атрибут земной жизни, который присущ тем, кто озабочен повседневностью. Если человек выходит за рамки обыденности, смотрит на страдание как на повод задуматься над своим жизненным путем, то тогда у него есть большой шанс достичь вершины мудрости и бессмертности. Важным понятием, связанным со страданием, является понятие смерти, ибо если все неизменно, то смерти нет, есть только переход в новое качество, так зачем страдать о том, что не уйдет. Мудрец не может умереть, т.к. нет абсолютного рождения и смерти, а есть Воплощенный, который вечен и Он лишь использует одно тело, а затем другое. Эти идеи, так или иначе, присутствуют в большинстве других направлений религиозно-философской мысли, но именно в «Бхагавадгите» все это имеет яркую и поэтическую форму [3, с. 102].

Религиозно-философские воззрения джайнов довольно широко раскрывают количество страданий для конкретного человека, и показывается зависимость многообразия страданий от ступеней, на которых человек в данный момент находится. Есть страдания от слабых омрачений, сильных омраченей, страдания от недостатка мудрости, от препятствующей процессу познания кармы, а ещё от кармы, искажающей поведение и кармы излишней чувственности. Одновременно у человека может быть до двадцати страданий [3, с. 84; 89].

В джайнизме страдание неотъемлемая часть жизни человека, и только количество различных страданий зависит от деяний человека, его активности в этом мире. Через медитации и соблюдение обетов можно очиститься от скверны и чувственной зависимости. Страдание это путь осознания своего предназначения в этом мире и путь к мокше (свободе). Только мудрый и смелый человек преодолевает страдания и возвышается. Джайны, безусловно, верят в жизнь после смерти, поэтому считают, что страдания не напрасны и имеют четкую направленность на преодоление земных соблазнов. Чем больше у человека появляется соблазнов в жизни, тем сильнее его страдания по их преодолению и тем важнее путь к очищению к дхарме.

Ещё более масштабно и наглядно раскрывается понятие страдания и пути освобождения человека от страданий в философии и религии буддизма. В Четырех Благородных Истинах страдание - это фактически все что есть в нашей жизни от самого рождения до последнего момента жизни, переходящего в смерть. В буддистской философии страдание в большей степени продукт самого бытия [4, с. 144], это не показатель неправедного поведения человека, а значит, оно есть и его не может не быть.

Буддисты объясняют, что для жизни человека характерны удовольствия, но очень важно то, что эти удовольствия не противоположны страданию, они с ним переплетаются и взаимодействуют как с прародителем, получая основу и обязательную оценку. В момент удовольствия хочется остановить сверхприятное мгновение, но оно не останавливается, наслаждение уходит, и мы начинаем страдать от прекращения наслаждения, от его скоротечности, просто от того, что оно ушло так быстро. В этом постоянный поиск наслаждения, стремление уйти от страдания, а получается ещё большее страдание приходит от осознания быстроты присутствия удовольствия в жизни человека. Страдание не только от конечности удовольствий, но и от ожидания смерти, 
которая может окончательно забрать эти удовольствия.

Четыре Благородные Истины говорят нам и о том, что влечение, желание, привязанность к жизни - это причины страдания. Жаждой влечения пронизана вся природа, стремление к приятному и отвращение от неприятного - основа жизни человека. Две стороны одной медали. Влечение ведёт нас к страданию, если бы этого не было, то и жизнь была бы совсем иной [5, с. 55]. Атрибутивность страдания здесь просто напрашивается и никуда от этого не уйти человеку.

О прекращении страдания мечтают люди, об этом очень много говорили философы, об этом в полной мере религиозные концепции разных времен и цивилизаций. Что же буддизм предлагает в отношении проблемы ухода или прекращения страдания? Вот тут как раз и появляется такое понятие как нирвана, при котором страдания больше нет, а значит, от него можно освободиться. Но каким способом, что для этого надо?

Если бытие всегда есть, значит, нирвана не уход от бытия, а скорее уход от страстей земных, от удовольствий и страданий, без которых невозможна жизнь человека. Все аффекты и влечения, питающие страдание, в нирване уходят, а значит, нет почвы для сохранения страдания. Не бытие уходит, а уходят лишние страсти, омрачения, привязанности. Вот именно так человек получает истинную картину бытия, появляется чистое восприятие мира. Достижение нирваны самая главная загадка буддизма, но рецепты представлены в Четвертой Благородной истине. Прекращение страдания - это важный для буддистов восьмеричный путь, в содержании которого присутствует три важных момента или фактора - мудрость, нравственность и психопрактика [5, с. 78]. Человек осваивает эти моменты своей жизни скрупулезно, они возносят его на новый плодотворный уровень. Возвышение над своим прошлым, над повседневностью и рутиной бытия - глубокий процесс самосовершенствования человека.

Фактор мудрости объединяет в себе всеобъемлющее понимание мира и убежденность в своих действиях. Этап нравственности включает правильную речь и правильный образ жизни. Момент психопрактики или сосредоточения определяется упорным трудом над собой и складывающимися обстоятельствами, моральным воспоминанием своего пути и идеальным обеспечением выхода в транс. Таким образом, буддизм находит ответы на самые сложные вопросы бытия человека, и с помощью глубокой религиозной философской традиции, а также с помощью хорошо организованной психопрактики, выводит человека на уровень осознания своего страдания и освобождения от него.

В Китае к атрибутивной модели представления о страдании можно отнести философию даосизма. Рассмотрим трактовку страдания и внутренних переживаний человека в «Дао дэ Цзин», одной из главных книг даосов.

Физические испытания, которые проходит человек в своей жизни, серьезно изнуряют тело, ослабевая его, но вот в то же самое время крепнет дух. Радость и гнев, удовольствия и страдания часто убивают дух, он разрушается, человек испытывает душевную боль, но вот тело вполне себе крепкое и готово к любым испытаниям. Человек испытывает серьёзные трудности, он как бы разрывается на части. Тело и дух две равнозначные составляющие человеческой натуры, а значит, могут исчезать не вместе, они самостоятельны в своих проявлениях [6, с. 108].

Даосы видят в страданиях слабость человека, его зависимость от телесной сущности. Главным предназначением страданий является закалка духа человека, возможность переносить все тяготы жизни стоически [7, с. 83]. Природа человека - растворение в мире и недопущение зацикливания на проблемах тела и общественной морали. Дух свободен тогда, когда тело не подчиняется своим капризам и не старается сломать предназначение своего существования.

Атрибутивность страдания определяет и Артур Шопенгауэр, который в своих рассуждениях определяет, что жизнь человека характеризуется большим и сложным участком между мечтаниями о приятном и реализацией этих заветных мыслей наяву. Человек погружается в страдание, так как воля не дает ему четкой обозначенной цели и не ведет его к конкретности смысла жизни. Воля без конкретной цели бесполезна, но она настолько сильна, что ведет человека неизвестно куда, не давая ему ни малейшей разгрузки. Любые второстепенные цели, полученные в течение жизни, приносят удовольствие и насыщение, но спустя мгновение все это превращается в проблему отсутствия дальнейшей цели и нового удовольствия, и так далее. Страдание это барьер между волей и целью, а раз цель воли фактически не достижима, то страдание постоянно с человеком [8, с. 225; 287].

Окружающий мир, как живой, так и не живой, устроен так, что нехватка одного приводит к пресыщению другим. Любое желание, пока оно не удовлетворено, представляет собой страдание. Человек, даже при очень скромных своих желаниях, достигнув их, начинает осознавать, что есть потребность в чем-то более внушительном и еще более желанном. Удовлетворенность не дает идеального положительного эффекта, так как возникает новое желание и новое переживание от не полученного результата.

Жизнь, по Шопенгауэру, - сплошные разочарования 
и страдания. В бытии человека лицевая сторона блестит от прекрасной ложности, а страдание скрыто от глаз, но оно правдиво и одержимо. Человеческая судьба - история страданий, все сплетено тесными узлами - неприятности, несчастья, проблемы, пресыщения, а жизнь - это то, что «отстрадать» $[9$, с. 114$]$.

Шопенгауэр определяет удовлетворение негативным, а страдание позитивным. В этом случае счастливый человек, удовлетворивший свои желания, значит, изначально счастья в человеке нет, оно возникает крайне прерывисто, чего не скажешь о страдании, оно с нами всегда. Счастье быстро исчезает и возникает новая потребность в желаниях. Человек, вспоминая страдания и лишения, испытывает удовлетворение. По сути, жизнь человека больше трагедия, хотя и изобилует яркими комедийными картинками. Неисполняемые никогда желания, всевозможные ошибки судьбы, неотвратимость смерти - все это атрибуты жизни человека, ее главное содержание.

Шопенгауэр подчеркивает, что страдание и смерть как два злых гения человека. Пессимизм по поводу жизни оборачивается некоторым оптимизмом в отношении смерти. При жизни страдания, после смерти их нет, а значит, она избавляет нас от страданий, но смерть губит индивида, губит саму сущность человека. И вот тут человек вступая с самим собой в спор, что легче и лучше, смерть или страдания, делает выбор в пользу страшных страданий, лишь бы уйти, хотя бы временно, от даже легкой смерти [10, с. 112; 113]. Смерть прекрасна тем, что она завершение жизни, наши страдания имеют концовку, а значит уже не такие страшные и всеобъемлющие. Если мы вдруг думаем о приближающейся смерти, то возникают уже не такие ужасные - страдания жизни.

От страдания можно «уйти» только осознав, что от него не избавиться. Человек, понимающий свою суть, суть воли и причинность страдания, может лишь нести с собой страдание как не иссякающий источник жизни. Мы, понимаем страдание исходя из двух приоритетов, что-либо страдание всегда принадлежит к какой-то важной цели, из-за не достижения которой, оно образовалось, либо страдание порождение удовольствия, требующего все нового нашего достижения, и без него мы не можем жить.
На рубеже XX - XXI веков исследователи в области религиоведения и философской антропологии, так или иначе, рассматривали атрибутивные аспекты страдания человека, но в большей степени анализируя древневосточные религиозно-философские направления, древнегреческие гедонистические концепции и иррациональные идеи Шопенгауэра. В данном исследовании, исходя из подробного изучения источников, перечисленных выше, и литературы рубежа XX - XXI веков, акцент сделан именно на атрибутивной модели преодоления страдания, которая в философии и религии появилась раньше, чем модусная, опирающаяся, прежде всего, на христианские идеи спасения, а потом подкрепленная новыми веяниями экзистенциальной философии [1, с. 7; 8; 9]. Спор о социально-нравственных и внутри личностных составляющих двух моделей продолжается с новой силой в наши дни, например, в философских, политических и религиозных спорах традиционных обществ Востока с быстро меняющимися личностными ориентирами на Западе. Впереди еще более ожесточенные идейные столкновения о будущем выборе человеком своего предназначения в этом мире, о соотношении в его сознании проблем жизни и смерти, о преодолении страдания.

Несмотря на яркие положительные стороны атрибутивной модели страдания, о которых речь шла выше, необходимо отметить, что страдание безначально и неизменно сопровождает все проявления бытия, но тогда смысл страдания состоит лишь в том, что оно просто указывает на саму жизнь, есть страдание - есть жизнь. По утверждениям рассмотренных философских направлений, жизнь вечна, но тогда какой смысл страдать, можно просто потерпеть и далее обрести полный комфорт души и тела, а может просто чистоту духа. В современных условиях некоторой деградации личностных ориентиров и общественных ценностей, не хотелось бы ориентироваться на мысли атрибутивного подхода о том, что страдание преодоление земных соблазнов, ведь это грозит потерей интереса к жизни и резким уменьшением жизнестойкости человека. Молодежи, да и более старшему поколению первой четверти XXI века, не очень подходит часть рецептов атрибутивности, ведь при таком раскладе при жизни невозможно преодолеть страдание, легче освободиться от жизненного бремени. Страдание все-таки должно нести некий инструментарий к самосознанию человека, к пониманию своего предназначения в этой жизни.

\section{ЛИТЕРАТУРА}

1. Токарев, Д.А. Жизненные смыслы страдания. Модели причин, проявлений и преодоления страдания / Д.А. Токарев. - Saarbrucken, LAP LAMBERT Academic PubLishing, 2011. 128, c.

2. Семенцов, В.С. Бхагавадгита в традиции и современной научной критике. - М., 1985. 212, с.

3. Железнова, Н.А. Учение Кундакунды в философско-религиозной традиции джайнизма / Н.А. Железнова. - М.: Восточная литература, 2005. 343, с.

4. Гроф, С. Надличностное видение: Целительные возможности необычных состояний сознания / С. Гроф. - М.: АСТ, 2002. 237, с.

5. Торчинов, Е.А. Философия буддизма Махаяны. - СПб.: Петербургское Востоковедение, 2002. 320, с. 
6. Дао дэ цзин. Книга пути и благодати - М.: Эксмо, 2002. 400, с.

7. Игнатьев И.П. Учение о человеке и проблемы нравственности в раннем даосизме // Социально-философские аспекты критики религии. - Л.: Нева, 1982. $154, c$.

8. Шопенгауэр, А. Собрание сочинений: в 5 т. - М.: Наука, 1993. - Т. 1. Мир как воля и представление. 395 , с.

9. Шопенгауэр, А. Свобода воли и нравственность / А. Шопенгауэр. - М.: Прогресс, 1992. 369, с.

10. Алейник, Р.М. Человек в философском постмодернизме / Р.М. Алейник. - М.: МИК, 2006. 224, с.

( ) Токарев Дмитрий Анатольевич (mityatokarev@mail.ru)

Журнал «Современная наука: актуальные проблемы теории и практики»

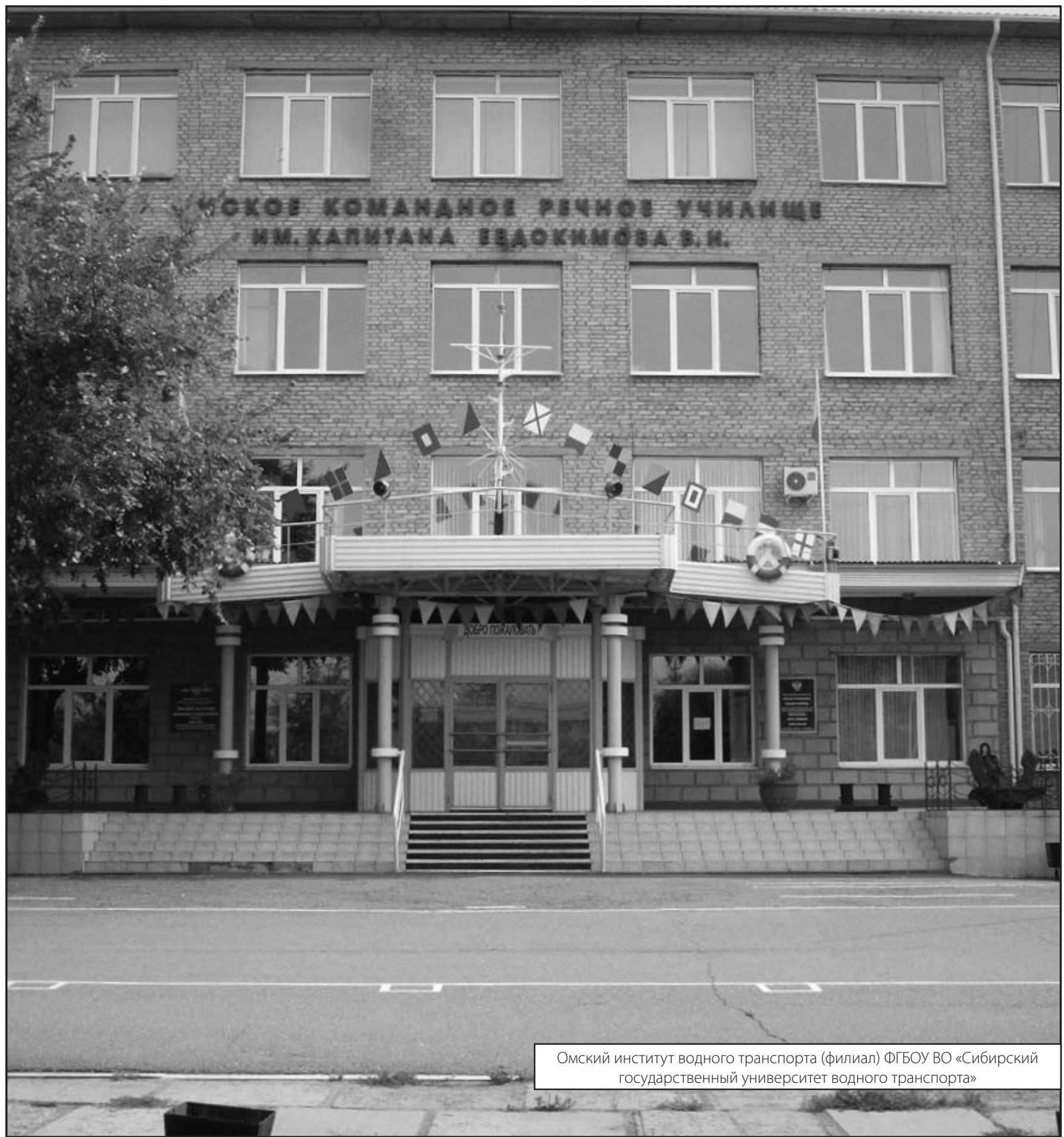

